\title{
Influence of the Bound Polymer Layer on Nanoparticle Diffusion in Polymer Melts
}

\section{SUPPLEMENTARY INFORMATION}

Philip J. Griffin ${ }^{1}$, Vera Bocharova ${ }^{2}$, L. Robert Middleton ${ }^{1}$, Russell J. Composto ${ }^{1}$, Nigel Clarke ${ }^{3}$, Kenneth S. Schweizer ${ }^{4}$, and Karen I. Winey ${ }^{1 *}$

${ }^{1}$ Department of Materials Science and Engineering, University of Pennsylvania, Philadelphia, PA 19104, USA

${ }^{2}$ Chemical Sciences Division, Oak Ridge National Laboratory, Oak Ridge, TN 37831, USA

${ }^{3}$ Department of Physics, University of Sheffield, Sheffield, S3 7RH, United Kingdom

${ }^{4}$ Department of Materials Science and Engineering, University of Illinois, Urbana, IL 61801, USA

*Corresponding Author: Karen I. Winey (winey@,seas.upenn.edu) 

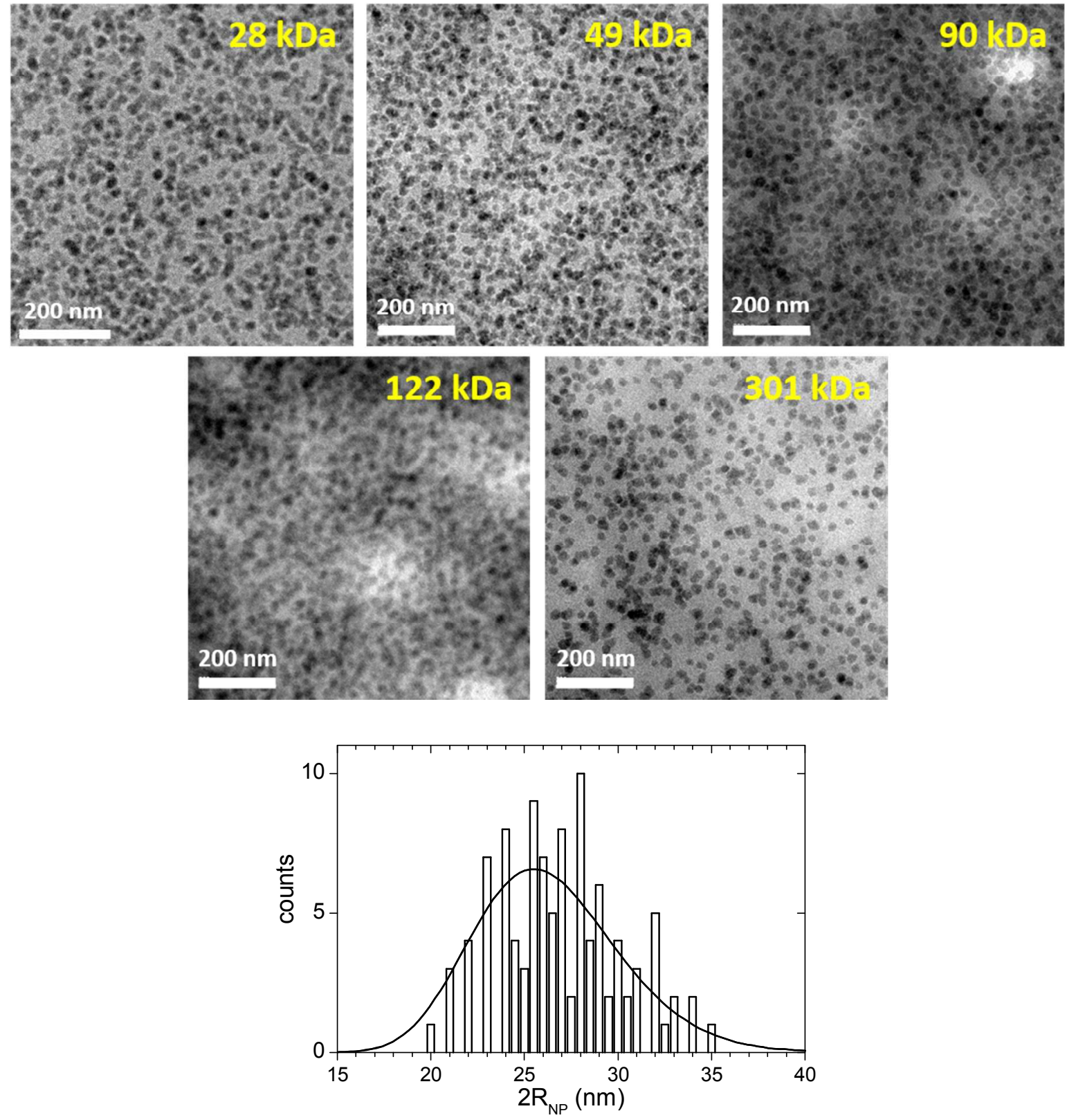

FIGURE SI. 1. Representative top-down transmission electron micrographs of $\mathrm{SiO}_{2} / \mathrm{P} 2 \mathrm{VP}$ nanocomposite tracer layer thin $(\sim 100-200 \mathrm{~nm})$ films with $30 \mathrm{~nm}$ PS top layer. The P2VP molecular weight is specified, and the NP concentration is approximately 10 volume percent in these tracer films. The bottom figure presents a histogram of NP diameters $\left(2 R_{\mathrm{NP}}\right)$ extracted from select micrographs. The line is a log-normal fit to the distribution, $f(x)=\frac{A}{x \sigma \sqrt{2 \pi}} e^{-\frac{(\ln x-\ln \mu)^{2}}{2 \sigma^{2}}}$, with geometric mean $2 R_{\mathrm{NP}}=26.1 \mathrm{~nm}$ and standard deviation $e^{\sigma}=1.2$. 

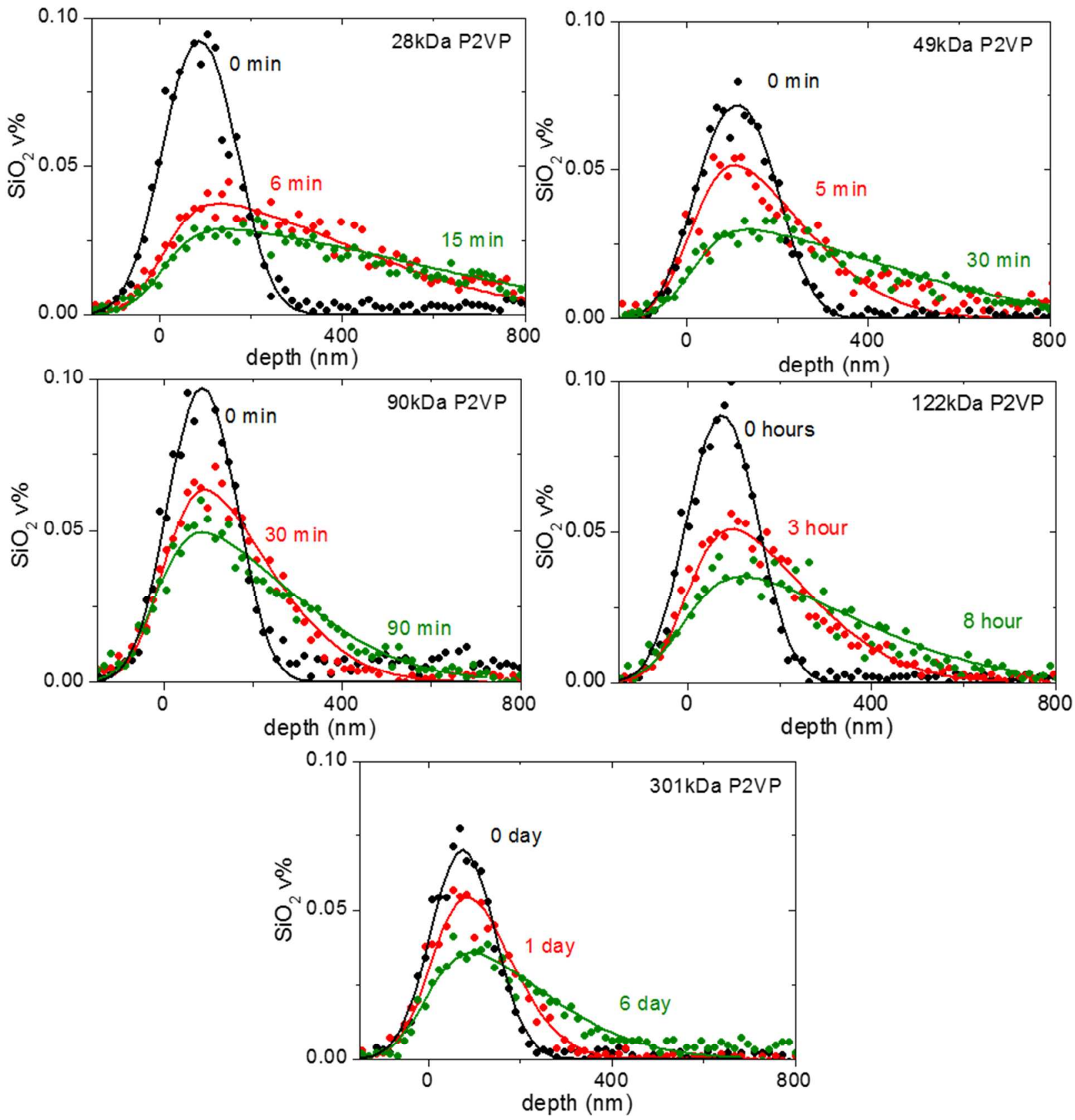

FIGURE SI. 2. Concentration profiles of silica nanoparticles infiltrated into P2VP-matrix samples after annealing at $180^{\circ} \mathrm{C}$ for specified annealing times. Polymer molecular weight is specified. Symbols depict measured data, and the solid lines depict fits to Fick's second law used to determine the NP diffusion coefficient. 


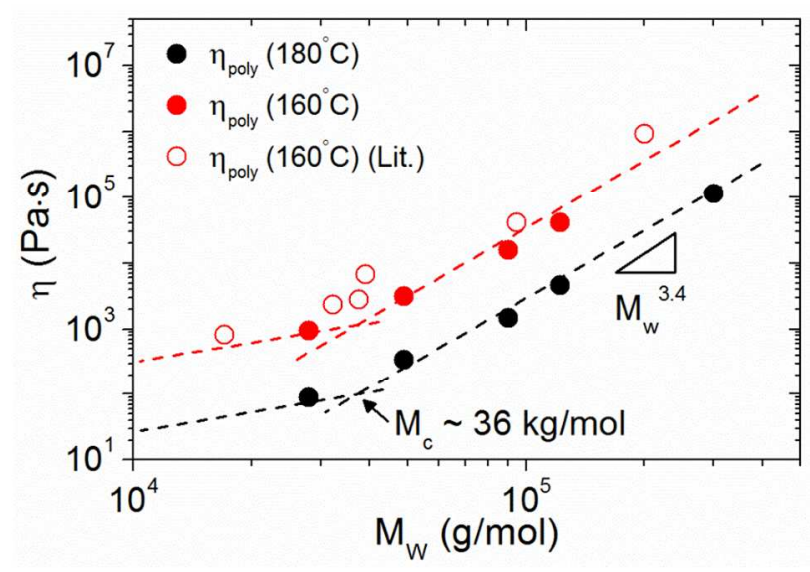

FIGURE SI. 3. Measured (solid symbols) and literature (open symbols) [1] data for the zeroshear viscosity of bulk P2VP at select temperatures. Dashed lines are guides to the eye showing expected molecular weight-dependence of viscosity in unentangled and entangled regimes. Oscillatory shear measurements of bulk P2VP were performed using a Rheometrics Solids Analyzer II using a sandwich fixture under small applied oscillatory strain (amplitude $=1 \%$ ). Samples were annealed at $190^{\circ} \mathrm{C}$ for 20 minutes, then cooled to the corresponding measurement temperature. The zero-shear viscosity was extracted from the low frequency imaginary shear modulus. 


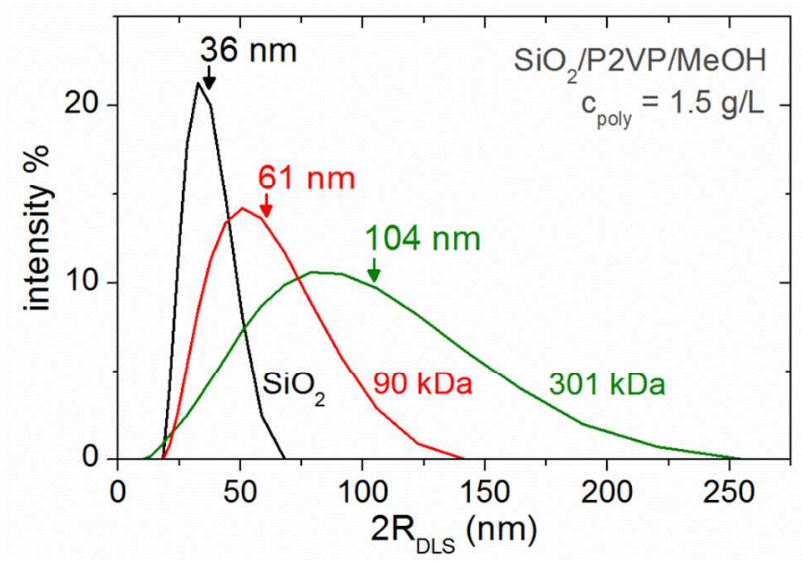

FIGURE SI. 4. Intensity-weighted size distributions of $\mathrm{SiO}_{2}$ nanoparticles in dilute $\mathrm{P} 2 \mathrm{VP} / \mathrm{MeOH}$ solution $\left(c_{\text {poly }}=1.5 \mathrm{~g} / \mathrm{L}\right)$ measured via dynamic light scattering (arrows depict geometric mean). The size distributions are well described by log-normal functions $\left(f(x)=\frac{A}{x \sigma \sqrt{2 \pi}} e^{-\frac{(\ln x-\ln \mu)^{2}}{2 \sigma^{2}}}\right.$, where $\mu$ and $e^{\sigma}$ are the geometric mean and standard deviation, respectively) that broaden and shift to larger diameters with increasing P2VP molecular weight, signifying the presence of bound polymer at the nanoparticle surface. These DLS-measured size distributions were independent of polymer concentration below $c_{\text {poly }} \approx 2.5 \mathrm{~g} / \mathrm{L}$. DLS measurements were performed using a Malvern Instruments Zetasizer Nano spectrometer. 
TABLE SI. 1. Geometric mean and standard deviation of intensity-weighted NP size distributions in dilute solution as measured by DLS.

\begin{tabular}{r|cc}
$\begin{array}{c}\text { P2VP molecular } \\
\text { weight }\end{array}$ & $\begin{array}{c}\text { Geometric mean } \\
\text { NP diameter }(\mathrm{nm})\end{array}$ & $\begin{array}{c}\text { Geometric standard } \\
\text { deviation, } e^{\sigma}\end{array}$ \\
\hline $\mathrm{SiO}_{2}($ no P2VP) & 36.0 & 1.3 \\
$28 \mathrm{kDa}$ & 41.6 & 1.38 \\
$49 \mathrm{kDa}$ & 51.9 & 1.51 \\
$90 \mathrm{kDa}$ & 61.0 & 1.51 \\
$122 \mathrm{kDa} a$ & 73.5 & 1.57 \\
$301 \mathrm{kDa}$ & 104.0 & 1.6
\end{tabular}

\section{SI. REFERENCES}

[1] Y. Takahashi, N. Ochiai, Y. Matsushita, and I. Noda, Polym. J. 28, 1065-1070 (1996). 